\title{
Fatigue Life Estimation of Damaged Integral Wing Spar Using XFEM
}

\author{
Khalid Ahmed ELDWAIB, Aleksandar GRBOVIĆ, Aleksandar SEDMAK, Gordana KASTRATOVIĆ, \\ Danilo PETRASINOVIĆ, Simon SEDMAK
}

\begin{abstract}
This paper presents the application of the extended finite element method (XFEM) in crack propagation simulation on the integral wing spar that should replace existing differential spar of the light aircraft UTVA 75. Numerical model of integral spar was developed in software Abaqus. Stress intensity factors (SIFs) were calculated using add-in Morfeo/Crack for Abaqus and obtained number of cycles that would propagate crack to certain length was compared to the experimentally obtained number of cycles for differential spar. Numerical analysis showed that integral spar with the same dimensions as differential spar has significant increase in fatigue life. Analysis that was carried out showed that XFEM could be efficient and cost beneficial tool for simulation of crack propagation in the 3D structures (such as wing spar) and that it should be used in the future for fatigue analysis of newly designed structures in all phases of development and production.
\end{abstract}

Keywords: crack propagation; fatigue life; stress intensity factor; XFEM

\section{INTRODUCTION}

To produce light-weight and cost-efficient airplanes engineers must use advanced materials and structural design techniques, as well as powerful analysis tools [1]. This is especially true for commercial aircraft with the wings composed of stressed skin, longitudinal stringers (in a shape of L- or U-beams) and aerodynamically optimized ribs. Stringers and ribs are mostly connected to skin by rivets and these joints are subjected to different loading combinations during the flight. Riveted structures (also known as differential structures) are still widely used; however, as the consequence of the loading cycles the skin expands and contracts resulting in metal fatigue. Due to the presence of drilled rivet holes, skin has many stress locations which may lead to crack initiation.

Fatigue crack initiation and growth issues associated with riveted structures are well understood and it seems difficult to get significant improvements in riveting technology. However, the development of other technologies (like laser beam welding), enabled production of so-called integral structures, which in turn reduced the riveted joint applications [2]. Integral structures, which enable skin and other elements to behave as a continuum, are more suitable for improvements. Compared to the conventional riveted structures, integral structures are lighter, easier to inspect and have fewer areas with high stresses suitable for crack initiation.

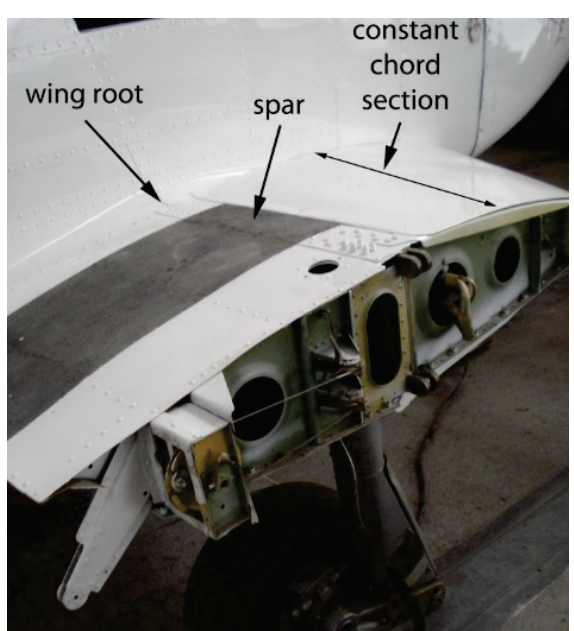

a)

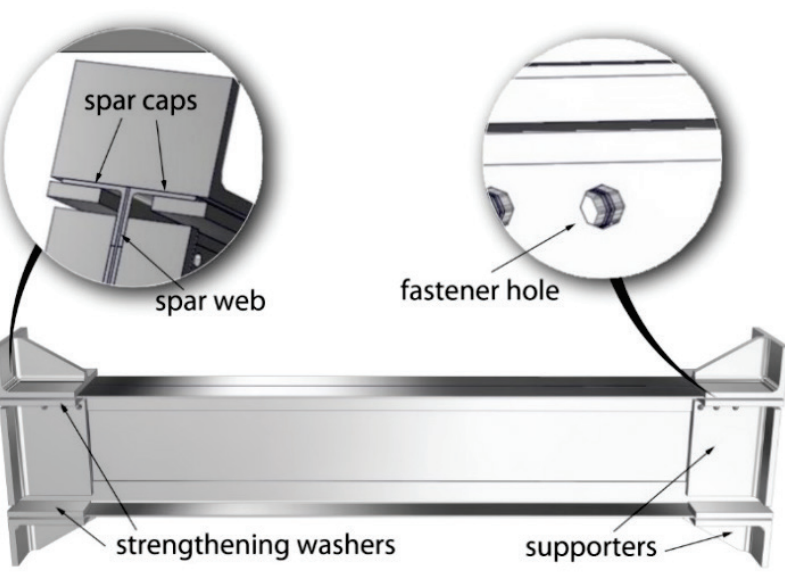

b)

Figure 1 (a) Wing root assembly of light aircraft UTVA 75, (b) The spar and supporting elements

During the flight, wing is exposed to substantial loading. The movement of aircraft generates lift force which holds the vehicle in the air, and - at the same time - bends the whole wing upright; therefore, the upper elements are under compression, while the lower are under tension [3]. The main load-carrying member of the wing is called spar [4] (Fig. 1(a)). Spar is positioned perpendicularly to the flow direction and is extended from the fuselage to the wing tip. It is usually composed of thin shear panel (called web) and flanges (called caps) at the top and bottom to take bending (Fig. 1(b)). Normally, the wing has 2-3 spars, while light airplanes mostly have wings with one spar. The spar carries almost all the bending and shear loads (more at its root than at the tip [5]), of which the lift force is the most dominant. Under service loading a fatigue crack may initiate from the most severe stress concentrator on the spar bottom cap. This crack can grow unnoticeably under service loading, first in the spar cap and - after the cap failure - in the spar web. Growth can lead to catastrophic failure if not detected during service and repaired [5].

Elements of the spar are mainly made of hardened aluminum alloys such as $\mathrm{Al}-\mathrm{Zn}-\mathrm{Mg}-\mathrm{Cu}$ (the 7xxx family) 
and $\mathrm{Al}-\mathrm{Cu}-\mathrm{Mg}$ (the 2xxx family). The mostly used alloy in light aircraft applications is 2024-T3 and standard specimens tested under constant amplitude loading provide data on how 2024-T3 behaves under different fatigue conditions [6]. However, the geometry of spar is not as simple as specimen's and highly influences the accuracy of fatigue life predictions obtained with specimen data. This is the reason why experimental verification of spar fatigue life under constant (and variable) amplitudes of loading must be carried out. But, even the smallest change in the geometry or material necessarily leads to new experiments, making the design process more expensive.

Suitable alternative to experimental verification is numerical modeling. In a case when a numerical model of the spar is developed all required changes are relatively easy to implement. Then new estimations of fatigue life can be obtained quickly and at low costs. However, the question that arises is: how can we be sure that the developed model is valid i.e. that obtained result is reliable and acceptably precise? It is obvious that an initial numerical model must be verified (through an experiment or analytically), and after that the values of damaged spar fatigue life, obtained by calculations for other loadings and/or materials, may be considered as good enough.

\section{NUMERICAL METHODS IN FATIGUE LIFE ESTIMATION}

The use of fracture mechanics techniques in the assessment of performance and reliability of damaged structures is on increase and the prediction of crack propagation in structure nowadays plays important part in fatigue life estimation. The stress intensity factor (SIF) is one of the most important parameters in fracture mechanics analysis. It sufficiently defines the stress field near the crack tip and provides fundamental information on how the crack is going to propagate. In most of the real situations, it is almost impossible to find an exact solution for SIFs. Therefore, the numerical methods are needed for SIFs estimation $[7,8]$.
Over the years, many numerical techniques such as finite element method (FEM), boundary element method (BEM), meshfree methods and extended finite element method (XFEM) have been developed to simulate the fracture mechanics problems. In XFEM, the conformal meshing is not required, hence, the modeling of moving discontinuities or crack growth is performed with an ease. The growth of the cracks and moving discontinuities are modeled by adding discontinuous functions into standard finite element approximation. The essence of the XFEM lies in subdividing the model problem into two distinct parts: mesh generation for the geometric domain (cracks not included), and enriching the finite element approximation by additional functions that model the flaw(s) and other geometric entities [9, 10, 11].

In $[12,13]$, the stress intensity factors of a slantcracked plate, which is made of 6061-T651 aluminum, was analyzed using XFEM and FEM in software ABAQUS and the results were compared with theoretical values. Numerical values obtained were close to the theoretical ones. In simulations of crack growth at different crack angles, the crack propagation angle values were closer to the theoretical values in XFEM method. Also, the accuracy and validity of fatigue crack growth curve were much closer to the theoretical graph in XFEM than in the FEM. Two numerical problems of stable crack growth in ductile material were solved in [9] to show the capability of XFEM.

Moghaddam et al. presented an XFEM procedure to investigate $2 \mathrm{D}$ crack propagation in elastic, homogeneous and isotropic three-point bending beam with initial crack. The modeling was done by the finite element software ABAQUS [14]. Some examples of planar and non- planar 3-D crack growth are solved to demonstrate the applicability and robustness of the proposed XFEM approach [15]. In [16] SIF of an Aluminum plate with central crack is computed using virtual crack closure technique (VCCT). The values obtained were compared with empirical values and displacement extrapolation method values and very good agreement was found.
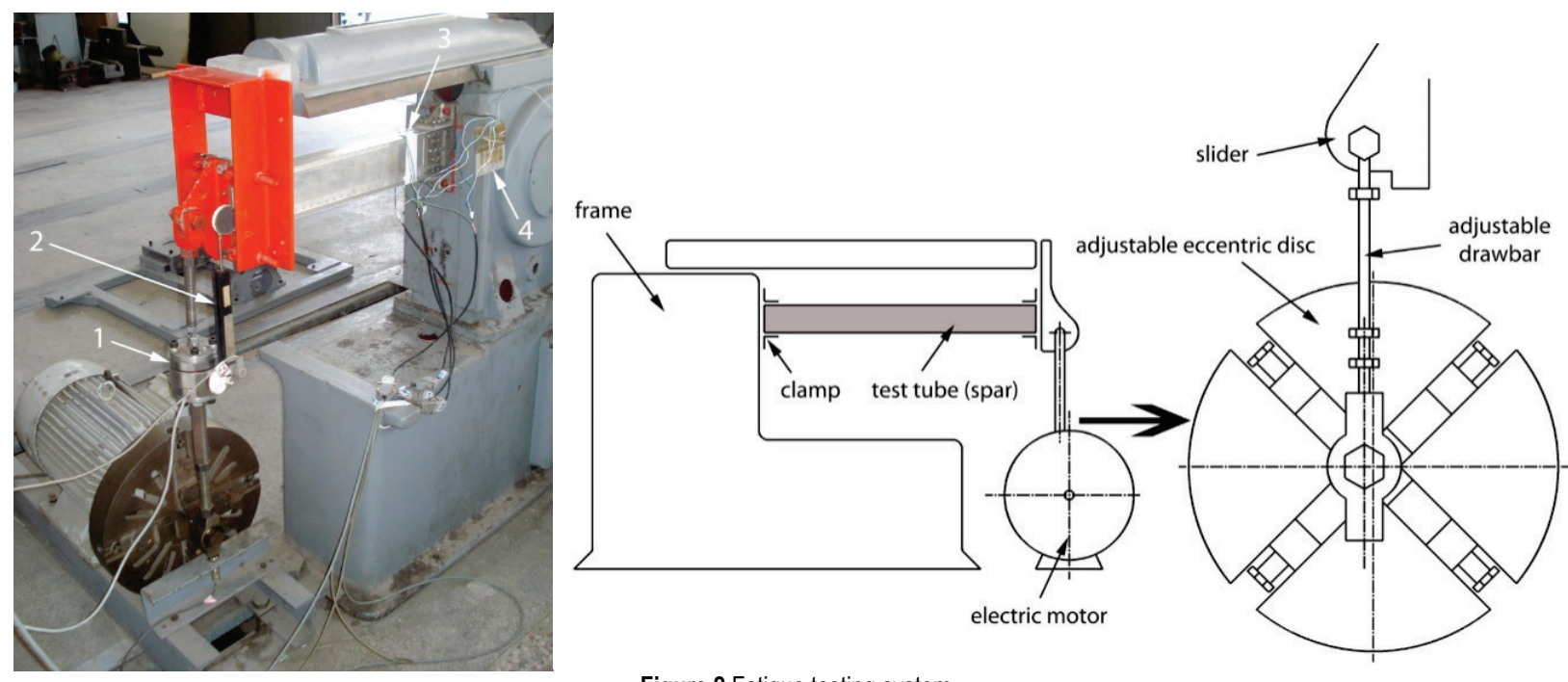

Figure 2 Fatigue testing system

The XFEM has also been used to calculate SIFs for problems involving multiple, interacting cracks, resulting from multiple site damage (MSD) [17, 18], as well as for the fatigue life estimation of the integral skin-stringer panel $[19,20]$. Finally, central crack has been simulated to verify XFEM procedure, [21]. 
Inspired by procedures described in above mentioned papers, as well as by experimental and numerical evidences of differential spar fatigue life presented in [22], authors of this paper decided to use XFEM for crack propagation simulation and fatigue life estimation of the integral AA2024-T3 wing spar that should replace differential spar of light aircraft UTVA 75 (shown in Fig. 1). Toward this end, numerical model of AA2024-T3 integral spar was developed and the number of loading cycles (to propagate crack to a given length) was compared with the number of cycles obtained in a case of AA2024-T3 differential spar. The later one was previously experimentally tested under diverse types of external loads using the equipment shown in Fig. 2, as explained in detail in [23].

\section{SIMULATION OF CRACK PROPAGATION AND FATIGUE LIFE ESTIMATION OF THE INTEGRAL SPAR USING XFEM}

During the experiment with narrow band random loading two cracks appeared. Load used (minimum value $+391.2 \mathrm{~N}$, maximum value $+2028.0 \mathrm{~N}$, frequency $12.5 \mathrm{~Hz}$ ), produced strong tensile stress in caps; consequently, visible crack appeared on the left cap below the support, after only 8,542 cycles. The crack began to spread rapidly towards the spar web, then changed its direction and continued along the cap at an angle of $90^{\circ}$ with respect to the original direction. After 39,450 cycles, another crack was spotted on the right spar cap, later determined to have occurred on the fastener hole. Cracks then continued to grow below the strengthening washers but were not visible. After 58,520 cycles, the test was stopped and the spar was examined to determine what was going on below the strengthening washers. Damaged spar after experiment is showed in Fig. 3. There was no visible damage on the spar web.

To simulate fatigue crack propagation, the FE model of integral spar, with dimensions equivalent to the differential spar, was made (Fig. 4). At the same time, it was decided to simulate simultaneous growth of two cracks since in above mentioned experiment two cracks appeared as a result of applied load. The initial penny shaped cracks were inserted at the left and right edge of spar cap (Fig. 4) next to the constraining zone. The reason for choosing these locations is that the cracks in the experiments with differential spars always appeared in that zone.



Figure 3 Damaged spar after experiment with narrow band random loading

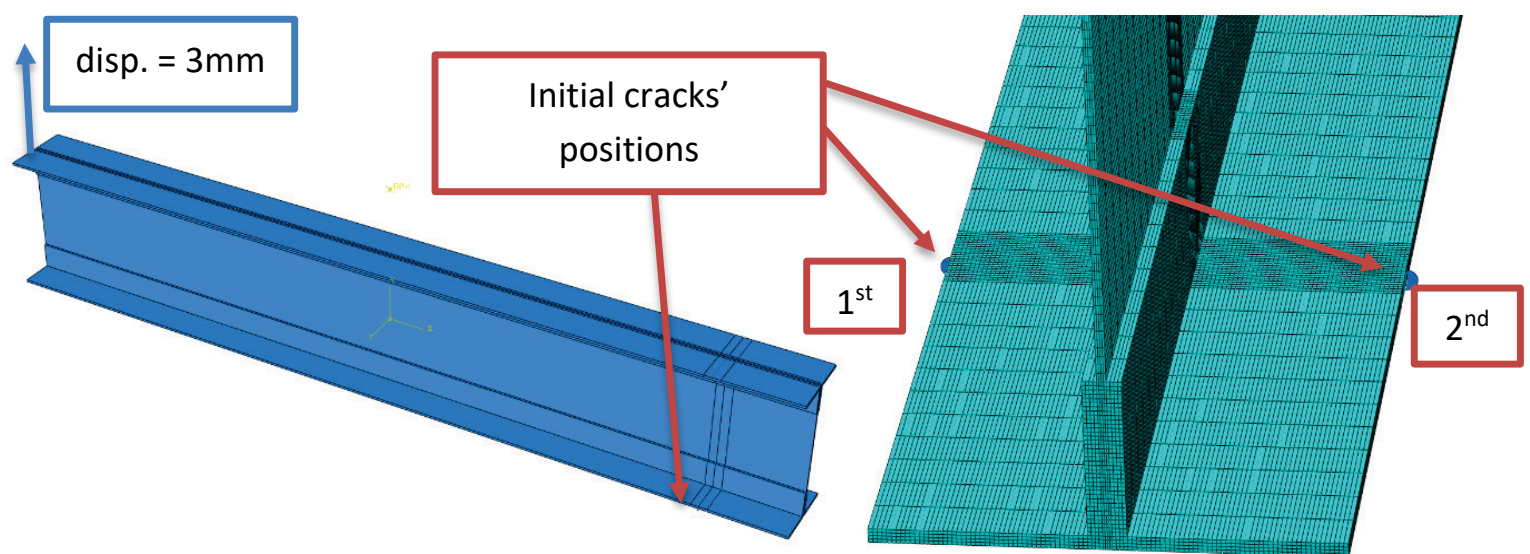

Figure 4 Integral spar geometry and FE mesh with initial penny shaped cracks (blue circles)

FE mesh was significantly refined in the areas where cracks were expected to spread for getting more precise values of SIFs at nodes on crack fronts. The mesh consisted of 278,616 three-dimensional eight-node linear brick elements with reduced integration (type C3D8R) and an average element size of $0.5 \mathrm{~mm}$ (average element size around the crack tip was $0.2 \mathrm{~mm}$ ). Initial cracks' lengths were $1 \mathrm{~mm}$ and cracks did not penetrate the entire thickness of the spar. The value of displacement used in the simulation was $3 \mathrm{~mm}$ and the material of spar was again aluminum 2024-T3. Crack growth simulation and SIFs calculations were performed using Morfeo/Crack for Abaqus.

After opening, the cracks were propagated in steps of approximately $1 \mathrm{~mm}$. Growth was not restricted to a single plane; instead, the crack could grow in the direction 
defined by kink angle, calculated within Morfeo/Crack for Abaqus. After twenty-two steps of propagation the FE model had a shape shown in Fig. 5 (right), with the first crack reaching the vertical wall of the integral spar. The path of the first crack on the horizontal wall of the spar was not straight but curved, like that obtained in the experiment with differential spar (Fig. 3). This path shape confirmed that boundary conditions and load applied as displacement were properly defined and that the numerical model simulated spar behavior adequately. It is interesting to mention that the second crack did not propagate after the $8^{\text {th }}$ step; deformation of spar caused by 1 st crack literally closed $2^{\text {nd }}$ crack and stopped its growth (when cracks' growth is restricted to a single plane, both grow at the same rate and $2^{\text {nd }}$ crack does not stop; but, this situation is supposed to be less realistic).

After opening, the cracks were propagated in steps of approximately $1 \mathrm{~mm}$. Growth was not restricted to a single plane; instead, the crack could grow in the direction defined by kink angle, calculated within Morfeo/Crack for Abaqus. After twenty-two steps of propagation the FE model had a shape shown in Figure 5 (right), with the first crack reaching the vertical wall of the integral spar. The path of the first crack on the horizontal wall of the spar was not straight but curved, like that obtained in the experiment with differential spar (Fig.3). This path shape confirmed that boundary conditions and load applied as displacement were properly defined and that the numerical model simulated spar behavior adequately. It is interesting to mention that the second crack did not propagate after the 8 th step; deformation of spar caused by 1 st crack literally closed 2nd crack and stopped its growth (when cracks' growth is restricted to a single plane, both grow at the same rate and 2nd crack does not stop; but, this situation is supposed to be less realistic).
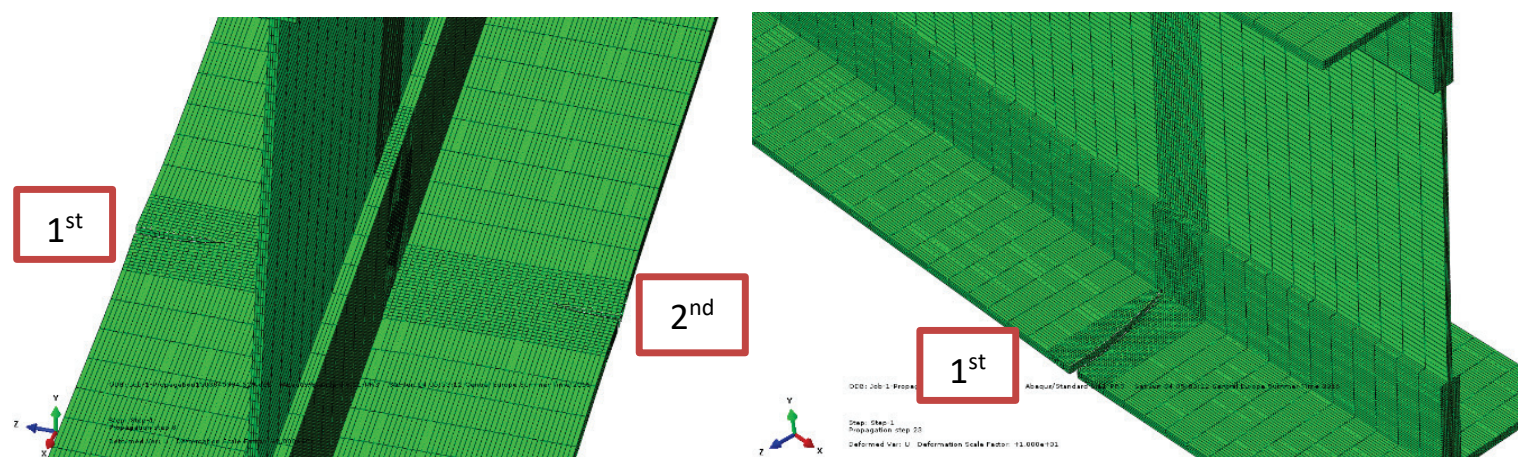

Figure 5 Cracks after the 8 th step (left) and 1 st crack after the $22^{\text {nd }}$ step of propagation (right)

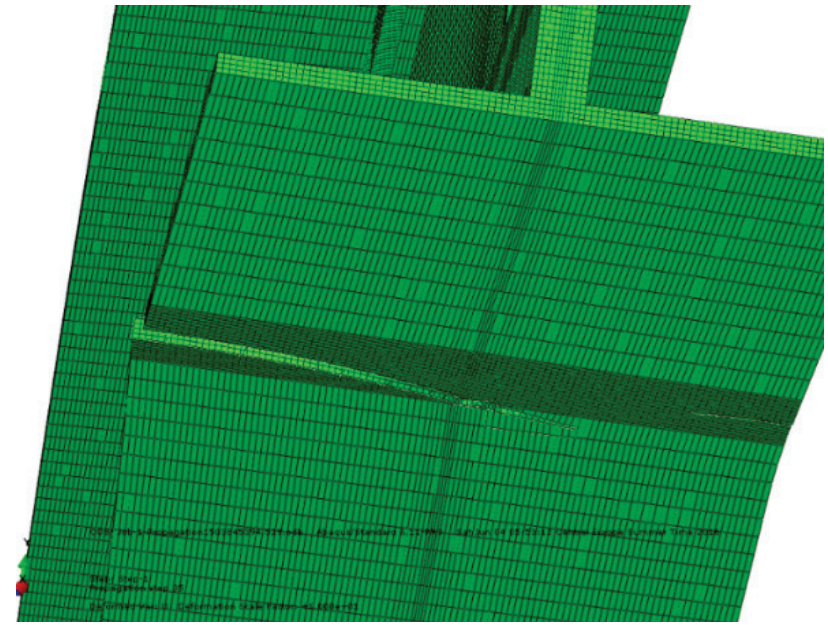

Figure 61 st front of the crack after 35 steps of propagation

First crack then split and two new fronts continued to propagate simultaneously in the horizontal wall of the spar ( $1^{\text {st }}$ front) and the vertical wall of the spar ( $2^{\text {nd }}$ front $)$. After the $35^{\text {th }}$ step of propagation (counting from the crack opening) the simulation stopped because the 1 st front left the area with refined mesh (Fig. 6) and Morfeo/Crack for Abaqus could not proceed with calculations (as an order of magnitude, it is recommended to generate elements 5 to 10 times smaller than the characteristic lengths of the initial crack both in the initial crack area and in the area where it is expected to propagate). Position of the $2^{\text {nd }}$ front after 35 steps of propagation is given in Fig. 7.

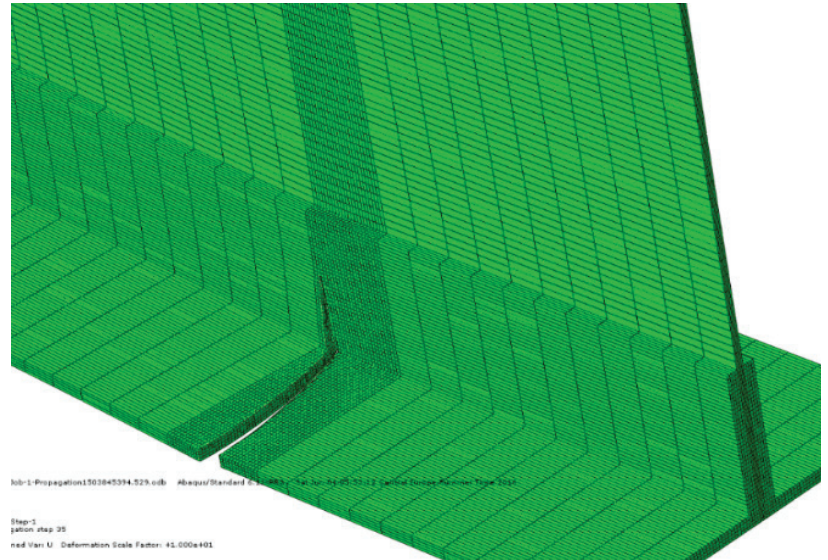

Figure $72^{\text {nd }}$ front of the crack after 35 steps of propagation

Stress intensity factors Mode I, II and III were calculated for each step; then, the equivalent stress intensity factor $K_{e q}$ was calculated for each node on crack fronts. The number of output values for each propagation step might be large and depends on the number of points on the crack front, which, again, results from the density of the FE mesh in propagation areas; therefore, values obtained during simulation had to be processed. Equivalent SIF values obtained for the first crack, along with estimated number of cycles for each propagation step, are shown in Tab. 1. Number of cycles was calculated using modified Paris-Erdogan law (the stress ratio $R=0.15$ used in calculations was identical to ratio kept in experiment with differential spar).

Tab. 1 indicates that the value of equivalent SIF increases until the $22^{\text {nd }}$ step, when $K_{e q}=792.263 \mathrm{MPa} \cdot \mathrm{mm}^{0.5}$. 
After that step it starts to decline, which coincides with the $1^{\text {st }}$ crack reaching the vertical wall of the spar. The equivalent SIF values continue to decline until the $27^{\text {th }}$ step when crack leaves the area between horizontal and vertical wall (which is thicker than other areas), and then starts to grow again until the last step. The number of cycles obtained for $1^{\text {st }}$ crack on integral spar (Tab. 1 and Fig. 8) shows that the initial crack (of length $1 \mathrm{~mm}$ ) will extend to $2 \mathrm{~mm}$ after approx. 198,000 cycles of applied displacement, while in the experimentally tested differential spar the initial crack extended to $2 \mathrm{~mm}$ after approximately 27,000 cycles (for the same applied displacement). Also, it grew up to $3 \mathrm{~mm}$ after the other 52,230 cycles compared to just 5,850 cycles in differential spar. The crack entered the area between the horizontal and vertical wall of the spar after 341,251 cycles compared to 45,000 cycles in differential spar.

Table 1 Values of equivalent SIFs obtained in XFEM simulation of crack growth in integral spar

\begin{tabular}{|c|c|c|c|c|}
\hline \multirow{3}{*}{ Step } & \multirow{2}{*}{\multicolumn{3}{|c|}{ Equivalent SIF $\left(K_{e q}\right)\left(\mathrm{MPa} \cdot \mathrm{mm}^{0,5}\right)$}} & \multirow{3}{*}{$\begin{array}{c}\text { Number of cycles } \\
\text { for each step }\end{array}$} \\
\hline & & & & \\
\hline & Max. value & Min. value & Mean value & \\
\hline 1 & 93.826 & 88.801 & 91.719 & 0 \\
\hline 2 & 152.502 & 149.587 & 151.375 & 198183 \\
\hline 3 & 194.855 & 191.828 & 193.819 & 52230.1 \\
\hline 4 & 229.092 & 226.499 & 228.344 & 25965.4 \\
\hline 5 & 260.933 & 259.291 & 260.547 & 16576.3 \\
\hline 6 & 291.804 & 290.072 & 291.435 & 11187.4 \\
\hline 7 & 317.247 & 316.374 & 316.905 & 8050.55 \\
\hline 8 & 352.698 & 351.549 & 352.109 & 5877.53 \\
\hline 9 & 374.155 & 372.906 & 373.416 & 4460.28 \\
\hline 10 & 415.091 & 413.892 & 414.682 & 3522.76 \\
\hline 11 & 449.562 & 448.396 & 449.129 & 2601.38 \\
\hline 12 & 473.899 & 472.919 & 473.658 & 2091.57 \\
\hline 13 & 522.874 & 519.630 & 521.578 & 1662.96 \\
\hline 14 & 555.674 & 552.286 & 554.547 & 1291.59 \\
\hline 15 & 584.024 & 578.592 & 582.290 & 1095.92 \\
\hline 16 & 638.751 & 635.255 & 637.780 & 882.429 \\
\hline 17 & 661.772 & 657.497 & 660.387 & 716.781 \\
\hline 18 & 720.133 & 714.993 & 718.642 & 602.786 \\
\hline 19 & 733.146 & 729.462 & 731.797 & 503.18 \\
\hline 20 & 779.894 & 769.054 & 775.773 & 445.093 \\
\hline 21 & 782.222 & 771.832 & 779.340 & 401.018 \\
\hline 22 & 793.353 & 789.838 & 792.263 & 382.973 \\
\hline 23 & 779.034 & 770.110 & 774.848 & 391.896 \\
\hline 24 & 715.610 & 692.728 & 705.825 & 452.095 \\
\hline 25 & 644.307 & 467.275 & 537.568 & 628.698 \\
\hline 26 & 558.247 & 488.218 & 531.361 & 1047.72 \\
\hline 27 & 590.477 & 493.666 & 531.149 & 913.837 \\
\hline 28 & 650.777 & 543.274 & 587.814 & 629.254 \\
\hline 29 & 823.883 & 653.519 & 688.550 & 627.077 \\
\hline 30 & 724.467 & 686.779 & 706.439 & 502.862 \\
\hline 31 & 733.845 & 716.974 & 726.257 & 483.992 \\
\hline 32 & 786.265 & 754.693 & 766.747 & 363.528 \\
\hline 33 & 839.233 & 800.253 & 816.207 & 295.627 \\
\hline 34 & 908.389 & 869.451 & 883.331 & 282.955 \\
\hline 35 & 920.845 & 906.537 & 914.249 & 235.858 \\
\hline 36 & 964.471 & 944.922 & 951.777 & 209.427 \\
\hline
\end{tabular}

Finally, propagation ended after 345,795 cycles compared to 50,743 cycles obtained in experiment. It must be noted that final crack lengths were not the same: crack in experiment riches $45 \mathrm{~mm}$, while length of crack in simulation is $36 \mathrm{~mm}$; nevertheless, fatigue life of integral spar is obviously much longer. Estimated number of cycles for integral spar is approximately 7 times greater than for differential spar under the same applied displacement. Tab. 1 indicates that the value of equivalent SIF increases until the $22^{\text {nd }}$ step, when $K_{e q}=792.263 \mathrm{MPa} \cdot \mathrm{mm}^{0.5}$. After that step it starts to decline, which coincides with the $1^{\text {st }}$ crack reaching the vertical wall of the spar. The equivalent SIF values continue to decline until the $27^{\text {th }}$ step when crack leaves the area between horizontal and vertical wall (which is thicker than other areas), and then starts to grow again until the last step. The number of cycles obtained for $1^{\text {st }}$ crack on integral spar (Tab. 1and Fig. 8) shows that the initial crack (of length $1 \mathrm{~mm}$ ) will extend to $2 \mathrm{~mm}$ after approximately 198,000 cycles of applied displacement, while in the experimentally tested differential spar the initial crack extended to $2 \mathrm{~mm}$ after approximately 27,000 cycles (for the same applied displacement). Also, it grew up to 3 $\mathrm{mm}$ after the other 52,230 cycles compared to just 5,850 cycles in differential spar. The crack entered the area between the horizontal and vertical wall of the spar after 341,251 cycles compared to 45,000 cycles in differential spar. Finally, propagation ended after 345,795 cycles compared to 50,743 cycles obtained in experiment. It must be noted that final crack lengths were not the same: crack in experiment riches $45 \mathrm{~mm}$, while length of crack in simulation is $36 \mathrm{~mm}$; nevertheless, fatigue life of integral spar is obviously much longer. Estimated number of cycles for integral spar is approximately 7 times greater than for differential spar under the same applied displacement.

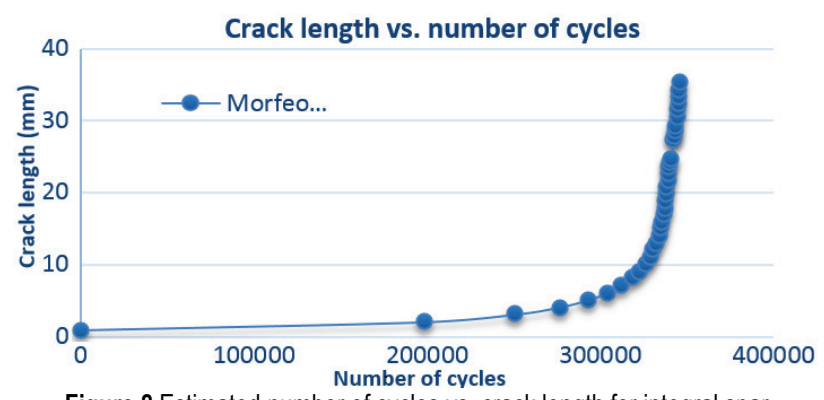

Figure 8 Estimated number of cycles vs. crack length for integral spar

\section{CONCLUSIONS}

To increase wing fatigue life and hence improve overall performance of light aircraft UTVA 75, integral AA2024-T3 wing spar, with the same dimensions as existing differential spar, was analyzed. As one of the first steps in analysis of new component, numerical model of the spar was created and fatigue crack growth was simulated. For that purpose, extended finite element method was used and, based on stress intensity factor values calculated on crack trajectory, fatigue life was predicted. Life to crack initiation was not estimated; main goal of the presented analysis was to compare residual life of damaged integral spar with the life of damaged differential spar obtained in experiment. Two cracks propagated on spar caps riveted to spar web until complete failure, while the web remained undamaged during the test. Contrary to the experiment, one crack on FE model of integral spar stopped after few steps of propagation, whilst other continued to grow and produced considerable damage on vertical wall (which has the same function as web of differential spar).

Comparison of numerical results and experimental values revealed that significant increase in fatigue life can be expected, justifying the idea of replacing the old concept with the new one. Although fatigue life estimation was carried out in an early stage of a design process, and a lot of work is yet to be done (particularly experimental work, 
as well as manufacturing and maintenance costs analysis), it has been confirmed that the development of the integral spar - as an alternative to a differential structure - was the step in the right direction.

\section{REFERENCES}

[1] Naveen, K., Suresh, S., \& Girish, K. (2012). A study of net section failure between two equal cracks in an infinite plate. International Journal of Modern Engineering Research (IJMER), 2(4), 2655-2661.

[2] Munroe, J., Wilkins, K., \& Gruber, M. (2000). Integral Airframe Structures (IAS) - Validated Feasibility Study of Integrally Stiffened Metallic Fuselage Panels for Reducing Manufacturing Costs, NASA/CR-2000-209337, May 2000.

[3] Grbovic, A. \& Rasuo, B. (2012). FEM based fatigue crack growth predictions for spar of light aircraft under variable amplitude loading. Engineering Failure Analysis, 26, 50-64. https://doi.org/10.1016/j.engfailanal.2012.07.003

[4] Maheswaran, N., Venkatesan, S., Sampath Kumar, M., \& Velmurugan, G. (2015). Study of weight optimization on spar beam for the wing of an aircraft. International Journal of Software \& Hardware Research in Engineering, 3(3), 72-79.

[5] Dutt, K. M. \& Kumar, D. B. N. (2013). Damage tolerance evaluation of the front spar in a transport aircraft wing. Int. J. of Innovative Research in Science, Engineering and Technology, 2(9), 5048-5055.

[6] Boyer, H. E. (editor). (1986). Atlas of Fatigue Curves, American Society for Metals, February.

[7] Souiyah, M., Alshoaibi, A., Muchtar, A., et al. (2008). Stress intensity factor evaluation for crack emanating from circularhole using finite element method. International Review of Mechanical Engineering, 2(4).

[8] Souiyah, M., Muchtar, A., Alshoaibi, A., et al. (2009). Finite element analysis of the crack propagation for solid materials. American Journal of Applied Sciences, 6 (7), 1396-1402. https://doi.org/10.3844/ajassp.2009.1396.1402

[9] Kumar S., Singh I. V., \& Mishra B. K. (2013). Numerical investigation of stable crack growth in ductile materials using XFEM. Procedia Engineering, 64, 652-660. https://doi.org/10.1016/j.proeng.2013.09.140

[10] Daux, C., Moes, N., Dolbow, J., et al. (2000). Arbitrary branched and intersecting cracks with the extended finite element method. International Journal for Numerical Methods in Engineering, 48, 1741-1760. https://doi.org/10.1002/1097-0207(20000830)48:12<1741::AIDNME956>3.0.CO;2-L

[11] Jovičić, G., Živković, M., \& Jovičić, N. (2009). Numerical simulation of crack modeling using extended finite element method. Journal of Mechanical Engineering, 55(9).

[12] Hedayati, E. \& Vahedi, M. (2014). Using Extended Finite Element Method for Computation of the Stress Intensity Factor, Crack Growth Simulation and Predicting Fatigue Crack Growth in a Slant-Cracked Plate of 6061-T651 Aluminum. World Journal of Mechanics, 4, 24-30. https://doi.org/10.4236/wjm.2014.41003

[13] Hedayati, E. \& Vahedi, M. (2013). Comparison Extended Finite Element Method with Finite Element Method and Theoretical Method for Computation of the Stress Intensity Factor, Crack Growth Simulation and Predicting Fatigue Crack Growth in a Slant-Cracked Plate of 6061-T651 Aluminum. World Applied Sciences Journal, 28(1), 20-26.

[14] Moghaddam, H. N., Keyhani, A., \& Aghayan, I. (2016). Modeling of Crack Propagation in Layered Structures Using Extended Finite Element Method. Civil Engineering Journal, 2(5).

[15] Shu, Y. \& Li, Y. (2016). A Simple and Efficient X-FEM Approach for Non-planar Fatigue Crack Propagation. Procedia Structural Integrity, 2, 2550-2557. https://doi.org/10.1016/j.prostr.2016.06.319

[16] Gopichand, A., Kumar, S., Sharma, A. V. N. L. (2012). Computation of Stress Intensity Factor of Cracked Aluminium Plate Using Virtual Crack Closure Technique. International Journal of Engineering Research and Applications (IJERA), 2(6), 460-465.

[17] Aldarwish, M., Grbović, A., Kastratović, G., Sedmak, A., \& Vidanović, N. (2017). Numerical Assessment of Stress Intensity Factors at Tips of Multi-Site Cracks in Unstiffened Panel. Structural Integrity and Life, 17(1), 11-14.

[18] Aldarwish, A., Grbović, A., Kastratović, G., Sedmak, A., \& Lazić, M. (2018). Stress intensity factors evaluation at tips of multi-site cracks in unstiffened 2024-T3 aluminum panel using XFEM. Tehnički vjesnik, 25(6), 1616-1622. https://doi.org/10.17559/TV-20170309133824

[19] Sghayer, A., Grbović, A., Sedmak, A., Dinulović, M., Doncheva, E., \& Petrovski, B. (2017). Fatigue Life Analysis of the Integral Skin-Stringer Panel Using XFEM. Structural Integrity and Life, 17(1), 7-10.

[20] Sghayer, A., Grbović, A., Sedmak, A., Dinulović, M., Grozdanović, I., Sedmak, S., \& Petrovski, B. (2018). Experimental and Numerical Analysis of Fatigue Crack Growth in Integral Skin-Stringer Panels. Tehnički vjesnik, 25(3), 785-791. https://doi.org/10.17559/TV-20170308110329

[21] Eldwaib, K. A., Grbovic, A., \& Kastratovic, G. (2017). Fatigue Life Estimation of CCT Specimen Using XFEM and Paris Law. Structural Integrity and Life, 17(2), 117-124.

[22] Ricardo Branco (Editor). (2015). Recent Trends in Fatique Design, Nova Science Publishers, Inc. New York. Chapter 2. Grbovic, A. \& Rasuo, B. Use of modern numerical methods for fatique life predictions, 31-75.

[23] Petrašinović, D., Rašuo, B. \& Petrašinović, N. (2012). Extended finite element method (XFEM) applied to aircraft duralumin spar fatigue life estimation. Tehnički vjesnik, 19(3), 557-562.

\section{Contact information}

Khalid Ahmed ELDWAIB, PhD student

Faculty of Mechanical Engineering, University of Belgrade,

Kraljice Marije 16, 11120 Belgrade, Serbia

Aleksandar GRBOVIĆ, Prof. PhD

Faculty of Mechanical Engineering, University of Belgrade,

Kraljice Marije 16, 11120 Belgrade, Serbia

E-mail: agrbovic@mas.bg.ac.rs

Aleksandar SEDMAK, Prof. PhD

Faculty of Mechanical Engineering, University of Belgrade,

Kraljice Marije 16, 11120 Belgrade, Serbia

E-mail: asedmak@mas.bg.ac.rs

Gordana KASTRATOVIĆ, Prof. PhD

Faculty of Transport and Traffic Engineering, University of Belgrade,

Vojvode Stepe 305, 11000 Belgrade

Danilo PETRAŠINOVIĆ, Prof. PhD

Faculty of Mechanical Engineering, University of Belgrade

Kraljice Marije 16, 11120 Belgrade, Serbia

E-mail: dpetrasinovic@mas.bg.ac.rs

Simon SEDMAK, Research associate

Innovation Center of Faculty of Mechanical Engineering

Kraljice Marije 16, 11120 Belgrade, Serbia

E-mail: simon.sedmak@yahoo.com 